\title{
THE USE OF RISK THEORY IN ERAMING SOLVENCY CONTROLS FOR NONLIEE INSURANCE COMPANIES
}

\section{MTOHAEL O. FINKELSTEIN †}

Regulatory proceedings frequently lead to decisions expressed in quantitative terms although both the controlling legal standard and key elements in the supporting evidence are expressed only in qualitative terms. Determining the percentage "fair rate of return" for a public utility is a prime example. No mathematical formula for arriving at the fair rate has yet gained acceptance, and the commissions, not surprisingly, have not explained how their quantitative conclusions follow from the qualitative evidence offered in rate proceedings. In fact, the rate decisions rest on unexplainable intuitive judgments.

In recent years, efforts have been made to circumscribe the role of subjective judgment in some regulatory proceedings by introducing objective methods utilizing mathematical techniques. ${ }^{1}$ The theory of these efforts has not been to eliminate subjective judgment from regulation but to drive it back from the ultimate decision into preliminary questions where traditional methods of legal analysis seem more rational because they are not called upon to produce numerical results.

For example, a utility entitled to earn the same rate of return as other enterprises of commensurate risk may be awarded a rate representing a subjective evaluation of the difference in risk between the enterprise being regulated and those used as standards. ${ }^{2}$ But if risk is equated with variability in earnings, statistical methods can be used to relate risk and rate of return on an objective basis. ${ }^{3}$ In the first or traditional method the key decisions are the subjective evaluation of differences in risk and their use to produce different rates of return.

$\dagger$ Lecturer in Law, Columbia University. A.B. 1955, J.D. 1958, Harvard University. Member, New York Bar.

The author is indebted to William B. Fairley and George H. Heyman for their respective contributions to this project. Insurance officials in Finland and the United States were generous in providing material. In particular, I would like to thank Kalevi Loimaranta of the Statistical Center for Nonlife Insurance in Helsinki; Dr. Errki Pesonen, Director of the Department of Insurance of the Finnish Ministry for Social Affairs; and William Gould of the New York State Department of Insurance.

This article is concerned solely with stock companies, which dominate the industry. Mutual companies are subject to different rules and present somewhat different problems.

1 See, e.g., In re A.T. \& T., 9 F.C.C.2d 30, 66-67 (1967); Southern Louisiana Area Rates, 40 F.P.C. 703, 847-72 (1966) (presiding examiner's decision).

2 See Leventhal, Vitality of the Comparable Earnings Standard for Regulation of Utilities in a Grozeth Economy, 74 YALE L.J. 989, 999-1001 (1965).

3 For an application of this method, see Western Union Exhibit No. 3, The Western Union Telegraph Co., No. 18270 (F.C.C. Oct. 2, 1968). 
In the second or "mathematical" method the key decision is the acceptance of variability in earnings as a fair surrogate for risk; the rest follows swiftly. It is the implicit premise of the mathematical model builders that the first method will inevitably involve unexplained acts of faith which foreclose progress toward greater correctness, while the second method may be explained, argued, and refined.

Mathematical models have received fairly wide acceptance in the social sciences and in some areas of business planning, but despite repeated efforts they have yet to influence in a significant way either the form or content of regulation in this country. In adversary proceedings, a determined and well-financed opponent can usually raise a cloud of objections sufficient to persuade the decisionmaker to avoid reliance on an imperfectly understood and potentially defective technique. ${ }^{4}$ Crossexamination or rebuttal testimony of this type is less difficult to assemble than one might think because mathematical formulation always requires simplification of the real situation and is thus forever open to the charge that some vital element has been omitted. The evolution of more sophisticated models will not eliminate these points of attack, but promises to focus attention on the legal standards by which the mathematics are to be judged. 5 Indeed, the ultimate problems of adapting mathematical theory to regulatory practice are more likely to be legal than scientific.

The gap between mathematical theory and regulatory practice is probably nowhere more significant than in the field of insurance, where a prime purpose of regulation is protection of solvency. A vast mathematical literature on the theoretical aspects of solvency control has developed in the past fifty years, but insurance authorities in the United States have remained impervious to its teachings, and solvency controls continue to be set by a generalized appeal to experience and intuition. This state of innocence may have significant social consequences. In addition to protecting the public from insurance company failure, solvency controls influence both the degree of competition and the extent to which insured risks are redistributed by reinsurance with other insurers in the nonlife insurance industry. If the current high levels of required minimum capital and reserves were reduced, new companies with less extensive resources would be encouraged as to both entry and growth and might prove more aggressive as competitors than established firms. A reduction in required reserves would also

${ }^{4}$ See, e.g., In re A.T. \& T., 9 F.C.C.2d 30, 68, 87 (1967); Southern Louisiana Area Rates, 40 F.P.C. 703, 858-72 (1966).

5 Experts have already disagreed on the standards question. Compare the requirements stated in Bell Exhibit No. 41 (statement of John W. Tukey) with those in F.C.C. Staff Exhibit No. 34 (statement of G. West Churchman), In re A.T. \& T., 9 F.C.C.2d 30 (1967). 
diminish the extent to which companies have to minimize their risks by passing them on to others through reinsurance. Conversely, the correctness of solvency controls grows in importance as the industry becomes more competitive and the margin for error shrinks. Minimum reserve rules will also effect the extent to which a company has free surplus to use in different lines of business, to distribute to stockholders, or to pledge for borrowings. The stringency of controls will thus influence not only dividends but also the growth of insurance holding companies and conglomerates.

In Finland, insurance authorities have drawn on the mathematical theory of solvency control in creating their regulations. Beginning in 1952, the Finnish Department of Instrance, concerned that inflation might be eroding company solvency, began to evolve minimum capital and reserve rules based on sophisticated mathematical techniques drawn from the branch of mathematical probability known as risk theory. ${ }^{6}$ Under this theory, the total amount of claims against an insurance company becomes a variable which may, with determinable probabilities, assume different values instead of being a set quantity as in classical actuarial science. The future financial position of a company is thus estimated on a probabilistic basis from mathematical models for distributions of numbers and sizes of claims, an approach which is needed for nonlife companies because total claim amounts fluctuate from year to year. ${ }^{7}$ Risk theoretic methods articulate the variables relevant to solvency and the interrelationships among various types of controls, and furnish an estimate of the degree of risk entailed in any particular choice. Of course, solvency controls cannot be determined on a purely technical basis. Determination of the level of risk or danger of insolvency which is acceptable requires a weighing of the risks of insolvency against the anticompetitive effects of high reserve requirements and controls on premiums. In making this policy judgment, however, technical methods are useful because the risk side of the policy equation cannot be appraised without them.

This Article will examine the evolution of the Finnish solvency controls and compare them with the rules used in New York State, the single most important American insurance regulatory jurisdiction. The Finnish methods are instructive because they suggest that the intuitive controls used in the United States could be relaxed, without endangering solvency, to promote competition among domestic companies and

6 There is a huge literature on risk theory. The most readable current book is R. Beard, T. Pentikätnen \& E. Pesonen, Risk Theory (1969), which also contains a good bibliography.

7 Risk theoretic techniques are not needed for life insurance because the force of mortality is relatively constant and predictable. 
to eliminate unnecessary reinsurance costs, thereby permitting reductions in premium rates. Reduction in reinsurance would also reduce or eliminate a United States dollar drain caused by payments of reinsurance premiums abroad. Apart from its immediate application to insurance, the Finnish method is worth understanding because it is probably the first successful effort to fuse sophisticated mathematical theory and practice in a regulatory process.

\section{The NEW YoRK RULES}

Protection against insurance company insolvency begins with statutory requirements for minimum initial surplus and capital. In the United States, statutes usually prescribe fixed dollar amounts for minimum paid-in capital which must be maintained at all times, and separate requirements for initial surplus, which may be expended. New York has the highest and most elaborate minimum capital requirements of any state, and since its statute applies to any insurance company doing business in New York ${ }^{8}$ it has broad extraterritorial reach.

The theory underlying the New York statute is that separate, fixed amounts of minimum capital should be required for each line of insurance and that additional initial surplus should equal fifty or one hundred percent of this minimum capital. ${ }^{9}$ The amounts currently required in New York are essentially unchanged from the 1939 revision of the insurance law. At that time they were almost doubled at the behest of the Department of Insurance, reflecting, it was said, the experience of the depression. ${ }^{10}$ Today, a New York stock casualty company ${ }^{11}$

8 N.Y. INs. LAw \$ 40 (McKinney 1966).

9 Capital, for present purposes, is defined as "the aggregate par value of all classes of shares of capital stock issued and outstanding." N.Y. INs. LAw $\$ 4(8)$ (McKinney 1966). Additionally required "initial surplus" is defined merely as an amount at least equal to a specified percentage of minimum paid-in capital: $50 \%$ for the kinds of business set forth in $\$ 311$ and $100 \%$ for the kinds set forth in $\$ 341$ (fire and marine). Id. $\$ \S 311(1), 341(1)$.

The kinds of insurance authorized in New York are divided into 23 classifications, $i d$. $\$ 46$, and requirements for minimum paid-in capital are established separately for each kind of insurance. See id. $\$ \$ 311(1)(a)-(e),(i), 341(1)$. When a company engages in more than one line of insurance business the requirements are cumulative, though mitigated by (1), for some classes, a flat $\$ 50,000$ reduction in minimum capital for each class except the first, id. $\$ 311$ (1) (f), and (2) overlapping requirements for fire, marine, and associated insurance, $i d$. $\$ 341$.

10 The capital requirements for casualty insurance and surety companies

have been substantially increased. This has been done by subdividing the insuring powers with regard to the amount of captial deemed requisite for the particular power. Due consideration has been given to the experiences of the recent depression and to the records of the Liquidation Bureau of the Insurance Department.

N.Y. State Ins. Dep'T, Insurance Law Revision of the State of New York, TENTATIVE DRAFT 1937 ix. The provisions of the Tentative Draft were adopted in 1939 virtually without change and have since been amended principally to reflect the allowance of multiple-line powers.

11 A stock casualty insurance company is a company organized as a stock insurance company, N.Y. INS. LAW $\$ 48$, and given power to do any of the kinds of business incorporated in $\$ 310$ by reference to $\$ 46$. 
desiring to write all types of casualty and surety business must have a total minimum paid-in capital and initial surplus ${ }^{12}$ of $\$ 2,700,000,{ }^{13}$ $\$ 1,800,000$ of which must be maintained. ${ }^{14}$ If fire and marine lines are added, total minimum paid-in capital and initial surplus rises by $\$ 1,000,000$, and minimum capital that must be maintained rises by $\$ 500,000$, subject to certain minor adjustments. ${ }^{15}$ A company engaged in all permitted lines of casualty, surety, fire and marine insurance would thus need total minimum paid-in capital and initial surplus of $\$ 3,550,000$, of which $\$ 2,200,000$ must be maintained. ${ }^{18}$

These requirements are supplemented by a statutory rule limiting the size of any single risk and by administrative guides against which unimpaired reserves are tested annually on the basis of statements filed with the New York Insurance Department. The statutory rule provides that a company's maximum single net retained risk ${ }^{17}$ may not exceed ten percent of its policyholders' surplus. ${ }^{18}$ As we shall see, this is a critical element in the pattern of controls, although it has never attracted much

12 The required amount of capital and surplus, see note 9 supra, must have been paid in to the company before a license to do any business may issue. $I d$. $\$ 48(8)(2)$.

13 See id. $\$ 311(1)$. A calculation deriving this result may be found in N.Y. State Ins. Dep't, 2 Examination of Insurance Companies 75 (1953) (table 2).

The statutes of other states are in general form similar to those of New York. See, e.g., CAL. INs. CODE $\$ \$ 700.01,700.02$ (West Supp. 1971) (Minimum paid-in capital is the lesser of $\$ 1$ million or the aggregate of a schedule of amounts ranging from $\$ 50,000$ to $\$ 250,000$ each for designated classes of insurance; surplus must equal $50 \%$ of minimum capital for insurers in business more than five years and $100 \%$ for others.); ILl. ANN. Stat. ch. 73, $\$ 625$ (Smith-Hurd Supp. 1971) (Minimum paid-up capital is $\$ 400,000$ for fire and marine companies and either $\$ 400,000$ or $\$ 600,000$ for casualty companies, depending on whether more than one type of casualty business is authorized; initial surplus is $50 \%$ of minimum capital for new companies while permanent surplus is required only for vehicle insurance.); PA. Stat. tit. 40, $\$ 386$ (Supp. 1971) (Minimum paid-up capital is $\$ 100,000$ to $\$ 300,000$ for fire and marine companies depending on the range of activities, $\$ 100,000$ to $\$ 300,000$ for casualty companies, depending on the range of activities, with certain exceptions for which higher amounts are required. A castualty company may transact all types of business with $\$ 1,200,000$. Minimum paid-in surplus is $50 \%$ of the subscribed total stock.); TEx. INs. CODE ANN. art. 2.02(4) (1963) (minimum paid-in capital of $\$ 100,000$ and surplus of $\$ 50,000$ for fire and marine insurers; $\$ 150,000$ capital and $\$ 75,000$ surplus for fidelity and castualty insurance; $\$ 200,000$ capital and $\$ 100,000$ surplus for all classes combined).

14 See N.Y. State Ins. Dep't, 2 Examinatron of Insurance Companies 75 (1953) (table 2).

15 See N.Y. INs. LAw §§ 311, 341 (McKinney 1966) ; note 9 supra.

16 This calculation may be found in N.Y. State Ins. Dep'r, 2 Examination of INSURANCE CoMpanIEs 77 (1953) (table 5).

17 N.Y. INs. LAw $\$ 47$ (McKinney 1966). Risks may be passed on or "reinsured" with an "assuming insurer." Id. $\$ 77$. A risk or portion thereof which is reinsured is deducted before the $10 \%$ limitation is applied. Id. $\$ 47$.

$18 \mathrm{Id}$. $\S 47$. "Surplus to policyholders" is a term keyed to the ongoing liquidity of the company's reserves and is thus to be distinguished from initial surplus. While initial surplus refers only to initially required funds in excess of minimum capital, "surplus to policyholders" is defined as the excess of "admitted" or qualifying assets, see $i d$. $\$ 70$, over the liabilities of the company. Id. $\$ 4(34)$. This is alternatively defined as "the sum of all capital and surplus accounts minus any impairment thereof." Id. For purposes of determining the maximum allowable risk, surplus to policyholders explicitly includes "any voluntary reserves." Id. $\S 47(a)$. 
attention, and was carried forward from the 1939 law without change or discussion. The basic administrative guide is an unwritten two-toone rule to the effect that net written premiums (written premiums remaining after deduction of premiums paid to reinsurers) in all lines of insurance except fire and marine insurance may not exceed twice policyholders' surplus. ${ }^{19}$ Put another way, the New York Insurance Department requires a minimum policyholders' surplus equal to fifty percent of net written premiums. For fire and marine insurance a special one-to-one rule requires a surplus equal to 100 percent of written premiums, reflecting the possibility of greater claim fluctuations in claims in these lines. In describing these rules, the Department stresses that these limitations are only benchmarks and that higher multiples are permitted if a company has shown a history of profitable underwritings. ${ }^{20}$

The two-to-one and one-to-one administrative guides were based on the observation of a former New York Commissioner of Insurance that companies with greater ratios tended to get into trouble during the 1930's and that the companies themselves have since followed these rules. ${ }^{21}$ A statutory requirement to this effect was included in a draft of the 1939 recodification of the New York Insurance Law as a restriction on dividend payments but was deleted to avoid controversy. ${ }^{22}$ The insurance law currently provides that aggregate dividends within any twelve-month period may not exceed ten percent of surplus to policyholders or 100 percent of investment income (whichever is greater) unless the Superintendent has previously found that the insurer will retain sufficient surplus to support its obligations and writings. ${ }^{23}$ This limitation may usefully identify questionable distributions but does not, in itself, constitute a substantive control since smaller distributions may imperil solvency, and the statute does not specify which larger ones involve peril.

Insurance regulators in the United States have generally accepted this arrangement: statutory minimum capital requirements are fixed dollar amounts and administrative controls are multiples of net written

19 See N.Y. State Ins. Dep't, Report of the Spectal Committee on Insurance Holding CoMpanies 46 (1968).

20 Interview with William Gould, New York State Insurance Commissioner, June 1971.

21 See N.Y. State Ins. Dep'T, Report of the Spectal Committee on Insurance Holding Companies 46 (1968).

22 Section 91.5 of the Tentative Draft of 1937 provided that a stock company could not pay a cash dividend unless its surplus to policyholders after the payment would be at least $50 \%$ of its net premiums written during the preceding year. The Department's comment on this provision was that, "[t] he limitations placed upon such companies in this section are no more severe than those observed by the more conservative casualty and surety companies." N.Y. STATE INS. DEP'T, INSURANCE LAW Revision of the State of New York, Tentative Drafi 1937, at 291.

$23 \mathrm{See}$ N.Y. INs. LAw $\$ 313$ (casualty and surety companies), 343 (fire and marine insurance companies) (McKinney Supp. 1970-71). 
premiums. Discussion of the rules has focused on the amounts of minimum capital and the multiple of net written premiums. Within the past five years, a number of states have amended their statutes to increase minimum required capital and policyholders' surplus, thus bringing their requirements closer to those of New York. ${ }^{24}$ On the other hand, New York's two-to-one rule has been criticized as "surely too stringent when used as a test of solidity," 25 and the National Association of Insurance Commissioners is reported to consider three-to-one a conservative ratio. ${ }^{26}$

Calculations developed below will show that New York's statutory minimum capital and reserve rules may impose an unnecessary burden on the industry to the particular detriment of smaller companies. It appears, however, that the defects in the present system will not best be cured simply by changing the specified amounts of minimum capital or the multiple of net written premiums used to test reserves. To gauge the need for the reserves currently required in the United States, and as a source for rules incorporating factors more relevant to solvency, the next section examines the controls used in Finland.

\section{The Finnish Rules}

When a new insurance companies law was enacted in Finland in 1952, the Department of Insurance was headed by Dr. Teivo Pentikäinen, a mathematician who had written some basic papers on applications of risk theory. Dr. Pentikäinen and others persuaded the Finnish government to accept risk theoretic considerations in framing statutory minimum capital rules and to write into the law express authority to use risk theory in connection with the equalization reserve. $^{27}$ The role of these methods expanded in 1965 when the Department of Insurance, under Dr. Erkki Pesonen (also a mathematician), refined some of the earlier techniques and established new rules for judging insurance company solvency.

\section{A. Statutory Minimum Capital}

The derivation of the Finnish statutory minimum capital rule begins with the principle that minimum capital should be large enough to leave only a small specified probability (on the order of 0.01 or less) that claims against a company would exceed the total of net premium

24 See Hearings on the Insurance Industry Before the Subcomm. on Antitrust and Monopoly of the Senate Comm. on the Judiciary, 91st Cong., 1st Sess., pt. 15, at 9026-27 (1969) (testimony of D. Pack).

25 N.Y. State Ins. Dep't, Report of the Special Compmitree on Insurance Holding Companies 46 (1968).

$26 \mathrm{M}$. Kaplan, Regulation for Insolvency in Hearings on the Insurance Industry Before the Subcomm. on Antitrust \& Monopoly of the Senate Comm. on the Judiciary, 91st Cong., 1st Sess., pt. 15, at 8962, 8966 (1969).

27 See text accompanying note 52 infra. 
income and working capital. ${ }^{28}$ Since net premium income (that is, net earned ${ }^{29}$ premiums less administrative expenses) is computed to cover expected claims, the function of working capital is to supply a reserve against years in which losses exceed the amounts expected.

The amount of working capital needed to cover, within any specified degree of risk, claims in excess of those expected requires complex calculations which depend on the number and sizes of the policies in a company's portfolio. For purposes of a statutory minimum capital rule it is necessary to make simplifying assumptions. The Finnish Supervisory Service assumed that net premium income was just adequate to cover expected losses; it thus assumed no profit. If, however, minimum capital requirements were simply based directly on net premium income, a company could always meet the statutory standards by increasing its reinsurance, since net premium income excludes premiums paid to reinsurers. To prevent this practice-which might tempt undercapitalized companies to carry excessive reinsurance-the Finnish statutory rule assumes that net premium income is one-half gross earned premiums. ${ }^{30}$

The degree to which actual claims may exceed expected claims is expressed in terms of the standard deviation, which is a measure of the spread or dispersion of a random variable about its mean or expected value. $^{31}$ Thus, if the total amount claimed is normally distributed, ${ }^{32}$ there is a 0.01 chance that it will be more than 2.3 standard deviations

28 The description in the text of the derivation of the rules contained in $\$ 5$ of the Finnish Insurance Companies Act of 1952 draws principally on an unpublished, undated memorandum of the Finnish Department of Insurance entitled, A Short Summary Concerning the System of Security Margin, Stabilization Reserve and Net Retention Applied by the Finnish Supervisory Office.

29 Earned premiums rather than written premiums reflect the risks carried. See text following note 89 infra.

30 Finnish Dep't of Insurance, A Short Summary Concerning the System of Security Margin, Stabilization Reserve and Net Retention Applied by the Finnish Supervisory Office 2. In marine insurance and received reinsurance, where the need for reinsurance is greater than in other lines, calculations are based on the premium after deducting the reinsurer's share. There is, however, a proviso that this premium figure after reinsurance shall be at least $50 \%$ of the gross figure. Finnish Ins. Companies Act of 1952, $\$ 5(3)$, translated in 1964 INs. IN FINLAND, No. 2, at 3. The combined effect of these rules is to permit net premium income for marine and received reinsurance to be as low as $25 \%$ of gross premiums, instead of $50 \%$ as in other lines.

31 The standard deviation provides a quantitative measure of the variability of random variables which may differ even though they have the same expected value (mean). For example, assume the expected amount of claims against an insurer is $\$ 500$ in a given year. This could mean that in most years there will be between $\$ 400$ and $\$ 600$ in claims. Alternatively, it could mean that some years are very good for the company and result in $\$ 200$ or less in claims and that other years are very bad and result in over $\$ 800$ in claims. The latter case would require more stringent solvency controls. The standard deviation, as defined above, distinguishes between these situations. The standard deviation squared (the variance) is defined as the expected value of the square of the difference between the variable and its mean value. infra.

32 For a discussion of the validity of assuming a normal distribution, see note 38 
above the expected amount, ${ }^{33}$ and only a 0.0001 chance that the departure will be more than 3.7 standard deviations above the expected amount. $^{34}$ In the present context, the standard deviation can be shown to be approximately equal to $\sqrt{K p M}$, where $p$ is the total net earned premiums and $M$ is the maximum realistically possible single clain. $K$ is a factor reflecting the variation in amounts claimed under individual policies, which increases as this variation diminishes and equals a maximum of 1.0 when individual claims are all equal to the maximum..$^{35}$ Based on empirical studies of variations in claims, it was known that $K$ usually ranges between 0.2 and $0.6^{36}$ Since larger values of $K$ lead to larger capital requirements, the Supervisory Service had reason to believe it was acting conservatively in setting $K$ equal to 0.67 .

Using these assumptions, minimum capital, $U$, may be written as

$$
\mathrm{U}=\mathrm{y} \sqrt{0.67 \mathrm{pM}}
$$

where $y$ is the number of standard deviation units from the expected claim amount sufficient to secure whatever degree of safety is required as a matter of policy, and $\sqrt{0.67 p M}$ is the standard deviation. ${ }^{37}$ The Supervisory Service decided that a risk of insolvency of 0.0001 would be permitted, which, assuming the total amount of claims to be normally distributed, ${ }^{38}$ is equivalent to 3.7 standard deviations. ${ }^{39}$ Thus $y$ was set equal to $3.7, p$ was assumed equal to one-half gross earned premiums for the reasons already given, ${ }^{40}$ and $M$ was estimated at one percent of

331 W. Feller, An Introduction to Probability Theory and Its ApplicaTIONS 167 (2d ed. 1957).

$34 I d$.

35 See R. Beard, T. Pentikärnen \& E. Pesonen, Rrsk Theory 58 (1969). On the assumption that claims occur randomly and independently, the standard deviation of total claims amount is $\sqrt{a_{2} n}$ where $a_{2}$ is the second moment of the distribution of individual claim amounts and $n$ is the expected number of claims. For a derivation, see $i d$. 22-23.

Setting $p=n m$ where $m$ is the mean amount of a single claim, and $K=\frac{a_{2}}{m M}$ yields the result given in the text. Id. 58-59.

36 Id. 58.

37 The total resource of a company with which to pay claims is $U+p$, where $U$ is the working capital and $p$ is the net premium income. Since $p$ must equal the expected amount of claims, $U$ must be an additional amount large enough to cover claim fluctuations within the specified degree of safety. Thus $U+p=p+y \sqrt{0.67 p M}$ or $U=y \sqrt{0.67 p M}$ as stated in the text.

38 There is a theoretical warrant for this assumption because the total amount of claims against a company is the sum of many small independent claims and the centra1 limit theorem of probability theory states that the sum of a large number of independent random variables will be approximately normally distributed regardless of their individual distributions. See, e.g., P. FREUnd, Matrematical Statistics 185 (1962). In fact, however, the choice of a normal distribution is not conservative because it understates the probability of large claims. This assumption was not used by the Supervisory Service in its subsequent development of more detailed reserve rules.

391 W. FELLER, supra note 33, at 167.

40 Text accompanying note 30 supra. 
gross earned premiums. When these values are inserted in equation (1) above, minimum capital equals about twenty percent of gross earned premiums. This formulation assumes, however, that $M$ increases in a linear fashion with gross premiums, an overstatement which causes capital requirements to rise too steeply as business increases. To correct this, a separate segment was added: the additions to capital for gross earned premiums over Fmk 4 million ${ }^{41}$ are at the rate of ten percent instead of twenty percent of gross earned premiums. ${ }^{42}$

This rule does not consider the costs of starting or winding up a company. For these purposes, the Finnish act requires a fixed initial capital, which may be expended, and a fixed permanent working capital in addition to the amount determined on the basis of gross premiums. An insurance company is entitled to a license to do business if it has initial capital of at least Fmk 1 million $(\$ 238,100)$ for fire and marine insurance, or at least Fmk 500,000 $(\$ 119,050)$ for other kinds of nonlife insurance. ${ }^{43}$ The issuance of a license is discretionary if initial capital is at least half the amounts specified. ${ }^{44}$ The fixed part of the permanent working capital is Fmk 200,000 (\$47,620) which covers all types of nonlife insurance. Thus the current rule is that fixed minimum working capital must equal $\mathrm{Fmk} 200,000$ plus about twenty percent of average gross earned premiums over the preceding three years up to Fmk 4 million and ten percent on average gross earned premiums in excess of this amount. ${ }^{45}$ A similar rule is the law in England. ${ }^{46}$

41 The Finnish mark (Fmk) currently converts at about 4.2 to the dollar. 1 THE EUROPA YEARBOOK 1970, at 616.

42 Finnish Ins. Companies Act of 1952, \$ 5, translated in 1964 INs. IN FinLaNd, No. 2, at 2-3. The amount was recently raised to Fmk 4 million to account for inflation. See Letter from Erkki Pesonen to Michael O. Finkelstein, Nov. 3, 1970. If $M$ were assumed to equal $10 \%$ of surplus, the legal maximum in New York, but the assumptions of the Finnish method were otherwise accepted, the minimum capital required would be $45 \%$ of gross premiums-close to New York's administrative two-to-one rule.

43 Finnish Ins. Companies Act of 1952, §4, translated in 1964 INs. IN FINLAND, No. 2, at 2. These figures include recent increases to account for inflation. See Letter from Erkki Pesonen to Michael O. Finkelstein, Nov. 3, 1970. No. 2 , at 2 .

44 Finnish Ins. Companies Act of 1952, §4, translated in 1964 INS. IN FinLANd,

45 Id. $\$ 5$, translated in 1964 INs. IN FinLAND, No. 2, at 2-3. The amount was recently increased to account for inflation. See Letter from Erkki Pesonen to Michael O. Finkelstein, Nov. 3, 1970.

To prevent companies from being wound up due to insufficient capital and free surplus, the Finnish law provides a further cushion: a company whose policyholders' surplus and reserves are less than twice the required minimum shall transfer each year to such surplus at least $10 \%$ of its business profit. Finnish Ins. Companies Act of 1952, $\$ 28$, translated in 1964 INS. IN FinLAND, No. 2, at 10.

46 Under English statutes, a nonlife insurer must have a surplus of at least $£ 50,000$ if the general premium income of the company in the previous year did not exceed $£ 250,000$, a fifth of that income if it exceeded $£ 250,000$ but not $£ 2,500,000$, or the aggregate of $\pm 500,000$ and one tenth of the amount by which that income exceeded $\pm 2,500,000$. Companies Act 1967, c. $81, \S 62(2)$. Note that the use of a stair step and the percentages of gross premiums are similar to those of Finnish law. 
Use of the ten percent segment of the rule, which lacks statistical support, and reliance on approximations instead of calculations for individual cases, make it uncertain that all companies will be protected, within the stated margin of safety, by this capital rule. The choice of that margin was itself a significant policy decision since the required reserves would be on the order of fifteen to twenty percent less if a safety margin based on a ruin probability of 0.001 instead of 0.0001 had been used. While changes in the approximating assumptions or in the safety margin would change the parameters of the rule, the significant fact is that minimum working capital is linked to premium volume, and the magnitude of the link has been defined by solvency considerations. Finnish companies are thus required to maintain sufficient surplus to cover claim fluctuations but are not unnecessarily burdened, as United States companies are, by minimum capital requirements when premium volume is small.

\section{B. Administrative Rules}

Statutory minimum capital requirements, which provide continuously applicable, rough limits, are supplemented by administrative rules against which reserves are tested more precisely at the close of each year. These rules, based on risk theoretic considerations, ${ }^{\mathbf{4 7}}$ were originally introduced in Finland in a context not directly connected with solvency.

Prior to 1952, because of high corporate tax rates, Finnish insurance companies found it more profitable to pay reinsurance premitums, which were deductible expenses, than to accumulate reserves from after-tax dollars. Reinsurance was frequently carried with foreign companies, and the funds flowing out of Finland had adverse effects on the balance of payments and were lost for domestic investment. To encourage retention of funds, the insurance law was amended in 1952 to provide for a new "equalization reserve" as a source of funds for years when claims exceed the amounts expected. ${ }^{48}$

In agreeing to permit tax deductible transfers to the equalization reserve, the Ministry of Finance insisted that changes in the reserve follow a definite formula. Accordingly, regulations of the Supervisory

47 General descriptions of the risk theoretic method may be found in Pentikäinen, Fluctuation Reserve: A Technique to Take Into Account the Fluctuation of the Risk Business When Calculating the Teclunical Reserves of Insurance Companies, 1970 INS. IN FINLAND, No. 1, at 2; and in Pesonen, Technical Reserves and Solvency, 1965 Ins. IN FINLAND, No. 2, at 5. A technical description appears in Porn, $A$ Study in Risk Theory and Its Application to the Computation of the Fluctuation Reserve Used in Finland, reprinted from SkandINAvISK AKTUARIETmSKRIFT 1 (1968).

48 Finnish Ins. Companies Act of 1952, §46, translated in 1964 INs. IN Fincand, No. 2 , at 14 . 
Service provide that in years in which the actual amount of incurred claims exceeds the expected amount, the equalization reserve is decreased by that difference, which is treated as income for accounting and tax purposes. In years in which the actual claims are less than expected claims, the difference is added to the equalization reserve and deducted from income. ${ }^{49}$ The equalization reserve thus acts both to smooth out variations in taxable income and as a reserve in lieu of reinsurance to cover fluctuations in claims. ${ }^{50}$

In permitting a tax deduction, the Finnish Ministry of Finance also insisted that the equalization reserve could not grow indefinitely without taxation, and exempted it only to the extent it could be regarded as cover for potential claim liability. ${ }^{51}$ The law authorizing an equalization reserve expressly endorsed a risk theoretic approach to the limit problem by providing that the reserve would be "calculated according to risk theory, to provide for years with unusually heavy losses." 52 In implementing this statute, the Supervisory Service decided that the equalization reserve would not be excessive as long as there was at least a 0.01 probability that claims in excess of those expected would exceed the amount reserved. A supplementary rule, however, provides that the reserve may grow to at least twice the company's maximum single net retained risk. ${ }^{53}$ These rules lead to amounts substantially larger than those needed to protect solvency because other company assets available for the payments are not considered. Because other assets are always available, it is in a sense artificial to view the maximum permitted reserve as necessary to cover fluctuations in claims, but the rule does at least put a cap on the equalization reserve.

American companies are currently in a position comparable to Finnish companies in the pre-1952 era because no tax deduction is

49 See Mintstry for Social Affatrs, General. Letter to Casuatty Insurance Coarpanies on the Basis of the Equalization Reserve 3-5 (May 31, 1965) [hereinafter cited as GENERAL LETTER].

50 See Porn, supra note 47, at 2 . New companies initially have a zero reserve. When the equalization reserve system was introduced, each company was permitted to establish an initial reserve, principally from a revaluation of surplus and secondarily by transfers from other technical reserves. As a company grows it needs an absolutely larger (although proportionately smaller) reserve to cover fluctuations in claims. To allow for growth, the Supervisory Service permits companies to assign an arbitrary percentage not exceeding $15 \%$ to the amount computed each year as expected claims in the formula governing changes to the reserve. GENERAL LETTER, sippra note 49, at 3-5. The result is a growth in the reserve at the average rate of the selected percentage. This percentage must be fixed in advance and may not be changed without a demonstration of necessity. Id.

51 See Pesonen, supra note 47, at 7.

52 Finnish Ins. Companies Act of 1952, § 46, translated in 1964 INs. IN FinLAND, No. 2, at 14 . In making the necessary computations, primary consideration must be given to protecting policyholders. Id. \$70, translated in 1964 INS. IN FINLAND, No. 2, at 21 .

53 General LeTter, supra note 49, at 3. 
allowed for additions to a reserve for claims not yet incurred. ${ }^{54}$ Since much reinsurance is carried abroad-there being a net outflow in 1968 of $\$ 98$ million from premiums paid by American companies to foreign companies ${ }^{55}$-balance of payment considerations suggest that a similar tax rule might be desirable here.

In 1965, the Supervisory Service refined the calculation of the maximum limitation. ${ }^{58}$ More importantly, it extended risk theoretic techniques to govern determination of total minimum working capital consistent with solvency. Several considerations led to this step. First, officials of the Service had been relying on intuitive judgment in assessing company financial conditions and they believed that impartiality would be furthered by objective rules. Second, the Service had only six examiners, and the lack of manpower argued for a simpler, mechanistic method for making the necessary determinations. Third, risk theoretic rules generate, in effect, an index of financial strength that can be used for advance warning of financial trouble. The Service regarded this as important because it is empowered to stop company operations if solvency is threatened and thus effectively to force a merger as an alternative to liquidation. ${ }^{\mathbf{5 7}}$

The approach adopted was similar in theory to that already described in connection with the minimum capital rules. ${ }^{58}$ The minimum equalization reserve is that amount which together with the other working capital of the company and net premium income is large enough so that there is only a small specified probability that losses will

54 INT. Rev. CoDE of $1954, \S \S 831,832$. But see id. $\S 832(\mathrm{e})$ (mortgage guaranty insurance losses resulting from adverse economic cycles).

55 The dollar drain from these payments has been of sufficient concern for the Department of Commerce to collect statistics. In 1968, United States insurance companies paid $\$ 407.9$ million to insurance companies resident abroad and received $\$ 170.6$ million on reinsurance assumed from abroad. Counting losses recovered from abroad on ceded reinsurance ( $\$ 291$ million) and losses paid abroad on assumed reinsurance ( $\$ 151.6$ million) there was a net outflow in 1968 of $\$ 97.9$ million, the highest in the twenty years since the survey was started. InSURANCE Advocate, Nov. 29, 1969, at 5 (U.S. Dep't of Commerce figures).

56 The principle adopted was that the equalization reserve would not be excessive if there were a 0.01 probability that claims in excess of those expected would exceed the reserve at least once in a 5 year period. The assumption is made that during the 5 years business remains at its current level. The principal component of this probability is represented by the chance that the reserve will be depleted by a series of bad years in which losses exceed expectations, the company completely exhausting its reserve in the fifth year. Because the probability of exhaustion is much greater in the fifth year, the Service accepts calculation of the 0.01 probability based solely on the chance of exhaustion in that year. See Central Associatron of FinNIst Insurance Companies, Computation of the Limits of the Equalization Reserve 9-11 (1967) [hereinafter cited as Computation MaNual].

57 Finnish Ins. Companies Act of 1952, §81, translated in 1964 INs. IN FrnLAND, No. 2 , at 22 .

58 The description in the text is drawn from the GenERAL IETter, supra note 49 , the Computation Manual, supra note 56, and from interviews with Dr. Erkki Pesonen, Director of the Department of Insurance, and Kalevi Loimaranta, head of the Statistical Center for Nonlife Insurance. 
exceed total reserves and net premium income in the coming year. A supplemental restriction requires reserves at least equal to the maximum single risk retained by the company. This prohibits the writing of a single policy larger than total reserves regardless of the likelihood of a claim under such a policy.

\section{Safe Bound Computations}

An exact computation of the reserves required by the theoretical statement of the objectives of these rules would not be simple. Most Finnish companies, however, find that their reserves are within authorized safe approximations (safe bound computations) for the minimum and maximum, which are extremely simple to compute, and thus are spared the more complicated computation. ${ }^{59}$ For purposes of these computations, premiums in the various lines of insurance are aggregated and treated as a single line.

The approximation for minimum required reserves is computed using a hypothetical company for which individual claims vary in number as in the normal case but are all equal in size to the largest realistically possible claim against the real company. The expected number of claims against the hypothetical company is deemed to be sufficiently smaller so that the expected total against the hypothetical company equals the expected total against the real company. The Supervisory Service assumes that the hypothetical company, which is subject to much larger but fewer claims, has a greater probability of being required to pay any given integral multiple of the maximum net retained risk than the real company. For this reason, the approximation is regarded as "safe." 60 While this assumption has been rigorously proved only for a special case, it appears true for all realistic situations, ${ }^{61}$ and the Service acts on that assumption. Use of the maximum net retained risk is as a practical matter an appropriate solvency control because companies frequently extend themselves in competing for the largest policies. Since under the Finnish solvency rules the maximum net retained risk is already taken into account in computing the required reserves, there is no need for a special limitation as under New York law. Accordingly, section 6 of the Finnish act simply provides:

59 A technical description of the safe bound method appears in Pesonen, Magnitude Control of Technical Reserves in Finland, 4 THE Astrn Bulletrn 248, 250 (1967).

60 To avoid the possibility that the rough step function form of the distribution of the total claims amount for the hypothetical company should cause a miss of the last catrastrophic claim, an amount equal to one claim of the stated constant size is added to the final result. Porn, supra note 47 , at 2 (equation $1^{\prime}$ ); Computation ManUal, supra note 56 , at 8.

61 Porn, supra note 47, at 15. 
The insurance company shall, by reinsurance or in some other way, carry on its business in such a manner that the interests of the insured are safeguarded by a sound relationship between the probable fluctuation of the company's loss costs and its working capital. ${ }^{62}$

The expected amount of claims is computed from the average loss ratio (incurred losses to earned premuims) for at least the five preceding years multiplied by earned premiums in the year just closed. The expected number of claims against the hypothetical company in the next year is computed by dividing the amount of expected claims in the year just closed by the maximum realistically possible single claim. If a trend in losses or premiums is noticed in any line of insurance, its influence may be taken into account by linear projections from the data of up to five preceding years. ${ }^{63}$

Claims in excess of those expected may be viewed as arising in two ways. First, the basic probabilities associated with the risk may increase due to some temporary change in conditions or as part of a long-term trend. Thus an exceptionally dry summer will create a heightened risk of fire and change for a time the basic probabilities associated with that risk. Second, changes may arise from simple random fluctuation in the number and amount of claims. In formulating the statutory minimum capital rule, the Service in effect took both classes of risk into account simply by requiring a safety factor of 0.0001 . In its administrative rules, these risks are considered separately. " $\mathrm{Bad}$ years" are accounted for by multiplying expected claims by a factor intended to increase those amounts to the level of a bad year. The factors required by the Supervisory Service are for the most part between twenty and forty percent, depending on the class of insurance. ${ }^{64}$ They were determined by examining variations in claims statistics for the various lines of insurance over a period of years, excluding extremely abnormal situations such as those produced by major depressions or war, and determining the proportion of the variation which could not within a 0.01 probability be attributed to chance fluctuations and so might be said to represent a change in the basic probabilities. The Supervisory Service believes the present estimates are somewhat overstated and intends to revise them as further data accumulate. Even though firm conclusions as to the proper magnitudes of these factors

62 Finnish Ins. Companies Act of 1952, §6, translated in 1964 INs. IN Fincand, No. 2 , at 3 .

63 Computation Manual, supra note 56, at 19.

64 General Letrer, supra note 49 (appendix 2). For example, liability insurance has a 0.20 factor, fire insurance a 0.40 factor, and forest insurance is in a class by itself with a 6.00 factor. After applying these factors to net premium income for each line, the amounts are aggregated and treated as a single line. Id. 
are not yet possible, their use protects against trouble for a large number of companies in a bad year which would make rescue operations by merger extremely difficult, particularly in a small country such as Finland.

Random fluctuations are those variations that would occur even assuming basic probabilities remained unchanged. Protection against such variations is provided by estimating from the expected total amount of claims (strengthened as previously described) an amount sufficiently large so that only a 0.01 probability remains that the actual claims amount would exceed the estimate.

Determining this 0.01 point requires a probability distribution for the number of claims. For this purpose, the Supervisory Service uses the Poisson distribution which has been used in mathematical descriptions of a great variety of phenomena in which discrete events occur randomly and independently. ${ }^{65}$ As applied to claims, the Poisson distribution defines the probability of the occurrence of any given number on the assumption that the occurrence or nonoccurrence of claims up to a certain point in time does not alter the probability that additional claims will be made thereafter. One may object that this assumption is not realistic in the insurance context because the occurrence of claims in the beginning of a year may indicate a greater probability that more of the same type are to follow. A model could be constructed on this basis, ${ }^{66}$ but the Service prefers to use the Poisson distribution and to account for a "contagion" of claims as a change in the basic probabilities by the method previously described. ${ }^{67}$ To simplify computations, a table for applying the Poisson model is furnished by the Supervisory Service.

The consequences of the safe bound formula may be summarized as follows. There is somewhat less than a 0.01 chance that underlying

65 The distribution of telephone calls coming into a switchboard is a frequently used example. See 1 W. Feller, An Introduction to Probability Theory and Its Applications 413-21 (2d ed. 1957).

66 The Polya model. See Porn, stipra note 47, at 417.

67 In these computations, earned premiums are premium payments plus (or minus) the net change in the reserve for unearned premiums. Similarly, incurred losses are losses paid plus (or minus) the net change in the reserve for unpaid losses. The premiums received and the losses paid are assumed to have been received and paid evenly throughout the year. The changes in the reserves are computed as if they occurred at midyear, and an annual interest factor of $5 \%$ is applied to bring them to that point. (This is done by multiplying the reserve at the close of the preceding year by $\sqrt{1.05}$ and the reserve at the close of the year by $1 / \sqrt{1.05}$. See ComputaIION MANUAL, supra note 56, at 8-9.) The 5\% figure was chosen as a conservative estimate of a company's earnings on its investments. Since the net earned premium and the reserve requirements are thus both computed as of the middle of the year, both these quantities are multiplied by an interest factor $(1 / \sqrt{1.05})$ to give the amounts required for the beginning of the year. Thus, at the beginning of a year, reserves must not be less than $(1 / \sqrt{1.05})(M y[v]-p)$ where the symbols have the meaning given in note 78 infra. 
conditions affecting claims in any line of insurance would so change that the expected claims in that line would exceed the amount computed as expected for a bad year. The probability that all lines would simultaneously have such a bad year is far less than 0.01 . In the extraordinary year which is simultaneously bad in all lines, the chance that claims would exceed the required reserves is less than 0.01 . The 0.01 probability is based on the assumption that claims in the various lines are independent; to the extent that they are correlated the probability of excess claims in the extraordinary bad year would be greater than 0.01 . As this statement indicates, the model is not so precise or so fully statistically supported that the degree of risk can be appraised with certainty. The model does, however, give some benchmarks for this risk, and one is able to say with some conviction that it is very small.

\section{D. "Exact" Computations}

When reserves lie outside the safe bound limits, a company must either increase its reinsurance if reserves are inadequate, or write additional policies or reduce reinsurance if reserves are excessive. But before the former is necessary it may make more exact computations to determine whether the theoretical requirements have been met. The method of computation has not been prescribed by the Supervisory Service, but a manual written by the Central Association of Finnish Insurance Companies describes methods which have the informal approval of the Service. ${ }^{68}$

Since claims may be made in any amount within policy limits, each claim size has a certain probability associated with it. In the more exact computations these probabilities are considered and are determined from historical statistics of the distribution of claim sizes in the same line of insurance. The Finnish Statistical Center for Nonlife Insurance has collected such statistics from a variety of sources, and from them computed the probabilities of different amounts of claims for different lines on an industrywide basis. For example, in private accident insurance, these statistics show that there is about a 0.50 probability that a claim will be ten dollars or less and a 0.99 probability that it will be approximately 887 dollars or less. ${ }^{69}$

In computing these probabilities, the basic difficulty encountered was that no very large claims were made, thus making it impossible on the basis of experience to determine their probability. The Statistical Center observed, however, that when probability was graphed against

es Computation Manual, supra note 56.

69 Id. (appendix 2). 
claim size on logarithmic paper, the lines were almost straight. It therefore argued that in the absence of other evidence the probabilities for larger claims could be estimated graphically by extending the lines. The Supervisory Service accepts this method of estimation because it appears to be reasonable and attributes a greater probability to large claims than almost any other plausible assumption involving the hypothesis that the probability of a claim decreases as its size increases. In fact, although this assumption is important in theoretical calculations, it is less significant in practice because reinsurance cuts off most of these very large potential claims. ${ }^{70}$ The Supervisory Service will accept a company's calculations based on the industry-wide probability distributions of a single claim, unless substantial reasons exist for believing that the shape of the claim distribution of the company is significantly different from that of the industry. This might occur if a company accepted groups of risks uniformly more dangerous or larger compared to its mean risk than was common in the industry.

Determining the probability distribution of total claims in all lines of insurance based on the probability distribution of individual claims presents a formidable calculation problem arising from the fact that any given total can result from a huge number of combinations of single claims. If there were 10,000 individual claims-not an unreasonable figure for a significant company-the required computations would be unwieldy and uneconomic even for modern computers.

Fortunately, ways of approximating these probabilities are known. In 1965 , at the time the requirements for a minimum equalization reserve were established, companies making the exact calculation used the so-called Monte Carlo technique. ${ }^{71}$ In this method a computer, using an input of random numbers and the probability distribution of a single claim, simulates the occurrence of claims and computes the total amount of claims a large number of times. The 0.01 probability point is then determined from the sample total of claims thus computed.

70 When safe bound computations are made, reinsurance of this type (excess of loss) is accounted for by considering only the maximum risk retained by the company. Computation ManUaL, supra note 56 , at 6,20 . When exact methods are used the problem of accounting for such reinsurance is slightly more difficult because the values of the components of the formulas depend on the probability distribution of a single claim and they change when the probability distribution is changed by the elimination of large claims. To facilitate computation, the Computation Mamual provides practical tables giving values of the formula components for a broad range of net retentions. Id. (appendix 3).

Particular difficulties arise in the case of quota share reinsurance when the proportion of the policies insured varies. Some companies have assumed, when computing the minimum required reserves, that the reinsurance level is uniformly equal to the minimum proportion reinsured, and have made the converse assumption in computing the maximum permitted reserves. Less draconian solutions to these complexities are still being explored.

71 Id. 4. 
More recently, the Supervisory Service has approved an extremely simple formula known as the normal power approximation which is sufficiently accurate unless the company has a disproportionate number of high risk policies. ${ }^{72}$ The Service permits the normal power approximation to be used if the maximum single retained risk is less than twice the standard deviation of the total amount of claims. ${ }^{73}$ In only one case has a company failed to meet this criterion. ${ }^{74}$ As in the case of the safe bound approximation, this method assumes that claims in the various lines are independent; to the extent they are correlated the risk of insolvency will be larger than that computed.

\section{Risk Analysis of the New York Rules}

Solvency controls represent a balancing of risks of insolvency against the burdens and anticompetitive effect of required reserves. Every control, explicitly or implicitly, embodies some risk policy. This section uses the Finnish methods to appraise the risk policies implicit in New York's statutory minimum capital requirements and in its two-toone and one-to-one administrative rules.

72 A derivation of the normal power approximation may be found in $R$. BEARD, T. Pentikäinen \& E. Pesonen, Risk Theory 43-47 (1969). Its accuracy is discussed and numerical examples given in Pesonen, NP-Approximation of Risk Processes, SkANDINAVISK AKTUARIETIDSKRIFT 158 (1968). Instructions for using this approximation which have the informal approval of the Supervisory Service may be found in Computation Manual, supra note 56, at 5-9. A published, slightly different version appears in Hovinen, Procedures and Basic Statistics to be Used in Magnitude Control of Equalisation Reserves in Finland, 5 THE AsTIN BulLETrN 227 (1969).

Using the normal power approximation as in the Computation Mannal, the minimum working capital required under the Finnish rules at the beginning of a year is given by:

$$
\mathrm{U}=\frac{1}{\sqrt{1.05}}\left[\mathrm{qp}+\mathrm{y} \sigma+\frac{1}{6} \frac{\mu^{3}}{\sigma^{2}}\left(\mathrm{y}^{2}-1\right)\right]
$$

Substituting the values for $\mathrm{y}_{0.01}$, we have:

$$
\mathrm{U}=.976 \mathrm{qp}+2.27 \sigma+7.17 \frac{\mu^{3}}{\sigma^{2}}
$$

See Computation Manual, sipra note 56, at 9. Each term of this expression is the sum of the indicated quantity for all lines of insurance. The first term, $q p$, represents the excess of expected losses in a bad year over those in a normal year. The second term, $y_{\sigma}$, is the number of standard deviations necessary to provide a safety margin (here 0.01 ). The third term adds an amount to account for the fact that the distribution does not die away symmetrically in both tails, but has greater area, or probability, in the right tail. The factor $\frac{\mu^{3}}{\sigma^{2}}$ is a measure of the skewness multiplied by the standard deviation of that distribution.

73 Computation Manual, supra note 56, at 7. The technical condition is that the measure of skewness referred to in the preceding note must be less than 2.0 .

73 Computation Manual, supra note 56, at 7.

74 Interview with Dr. Erkki Pesonen, Director of the Dep't of Insurance, Finnish Ministry for Social Affairs, in Helsinki, June 1970. 
Following the Finnish model, we may view a regulatory authority as making separate policy decisions concerning respectively the scope and the degree of protection from risk. The scope of protection is the extent to which provision is made for changes in basic conditions affecting risks. In the Finnish model, questions of this sort were resolved by making a bad year allowance for each line of insurance, determined from past statistics of abnormal variations of claims in that line. ${ }^{75}$ A twenty percent allowance for a line means that in a bad year expected claims would be twenty percent greater than in the current year. In determining these bad year factors, the Service omitted extremely abnormal years, such as those involving major wars or economic depressions, on the ground that protection from such abnormalities was not worth the cost. Presumably bad year factors based on domestic statistics would be different from the Finnish factors, and the difference might be substantial if regulatory authorities here adopted different policies with respect to the remoteness of the risks considered. ${ }^{76}$

The second policy decision is the degree of protection from fluctuation in claims that occurs under the conditions assumed to exist. In the Finnish model, the Supervisory Service assumed the conditions of the hypothetical bad year and permitted a fluctuation risk ${ }^{77}$ of 0.01 , thus allowing a risk of one in a hundred that in such a year claims would exceed the amounts reserved. Obviously, the 0.01 choice was arbitrary, probably more reflective of a cutoff point commonly used by statisticians in testing hypotheses than a special choice relating to insurance. The risk that claims will in fact exceed the reserves is far smaller than 0.01 since there is only a small probability that the bad year situation would be realized in any line and a much smaller probability that it would be simultaneously realized in all lines.

The use of separate bad year and fluctuation risk factors in effect divides variations in claims into two segments. Mathematically, any given reserve could be the result of different combinations of bad year and fluctuation risk factors which work in opposite directions: the greater the allowance for bad years, the smaller the fluctuation risk, and conversely. Since the New York rules do not specify either risk factor, we must relate each rule to pairs of values, each pair being equivalent in total risk to the rule being tested.

\footnotetext{
75 An abnormal fluctuation was defined as one that would not occur within a 0.01 probability assuming that current premium rates represented expected losses. The allowance is the percentage by which current expected losses would have to be increased so that losses in the bad year could have occurred within a 0.01 probability.

76 Other things being equal, one might expect bad year factors to be smaller for United States companies due to their much greater size.

77 The fluctuation risk is the probability that the total claims amount will exceed the amounts reserved.
} 
In computing these effective policies, the "exact" method of the Finnish system cannot be used since it depends on the probability distribution of claims derived from Finnish statistics, and we have no assurance that the probability distribution of domestic claims would be similar. The safe bound approximation, however, does not depend upon any particular situation or characteristic of Finnish companies, but only on the general assumption that claims are random and, to a degree, independent events. There is no reason to believe the claims process on this basic level is different in the United States. Table I, which follows, is based on the safe bound approximation as applied to established companies-those not experiencing significant growth-whose earned premiums may be taken to equal their written premiums. It pairs the values for the bad year factors and the fluctuation risks that would lead to the same reserves as the two-to-one rule, assuming a maximum single net retention equal to the New York limit, ten percent of policyholders' surplus.

\section{TABLE I ${ }^{78}$}

Risk Equivalents of the Two-to-One Rule (Established Companies)

\begin{tabular}{ll|l|l|l|l|l|l}
\hline Bad year factors & $\ldots \ldots \ldots$ & 0 & 0.10 & 0.20 & 0.30 & 0.40 & 0.50 \\
Fluctuation risk 79 & $\ldots \ldots$ & 0.002 & 0.005 & 0.01 & 0.03 & 0.05 & 0.08 \\
\hline
\end{tabular}

78 The probabilities shown in Table I are from E. Mounna, Porsson's ExponenTIAL Binomial Limrt (1942) (table II). A $50 \%$ loss ratio (losses to earned premiums) has been assumed.

A sample calculation is set out below. Let:

$\mathrm{p}=$ net premium income carried during the year $=$ expected claims amount for the year (by assumption),

$\mathrm{M}=$ maximum single net retained risk,

$q=$ bad year factor,

$\mathrm{U}=$ surplus to policyholders at the beginning of the year, and

$\mathrm{y}_{a}[v]=$ the number of claims, such that, assuming a Poisson process with $v$ as the expected number of claims, there is an a probability that the number of claims will equal or exceed this number.

In the Finnish system,

(1) $v=\frac{(1+q) p}{M}$ (General LeTTER, supra note 49, at 2). $v$ is rounded upwards to the next number appearing in tabulations of the Poisson distribution.

The Finnish safe bound rule is:

$$
\mathrm{U} \geq \operatorname{Max}\left\{\mathrm{O}, \frac{1}{\sqrt{1.05}}\left(\mathrm{My}_{a}[v]-\mathrm{p}\right)\right\}
$$

See Porn, supra note 47 , at 15 . The minimum permissible $U$ is defined by the equality portion of the equation, yielding:

$$
\begin{gathered}
\mathrm{U}=\frac{1}{\sqrt{1.05}}\left(\mathrm{My}_{a}[v]-\mathrm{p}\right) \text { or, } \\
\mathrm{U}+.976 \mathrm{p}=.976 \mathrm{My}_{a}[v] .
\end{gathered}
$$


For established companies whose largest single risk is equal to the legal maximum, Table I shows that the two-to-one rule is equivalent, at one extreme, to the assumption of no change in basic conditions in a bad year and a fluctuation risk of 0.002 . At the other extreme, expected claims in a bad year are assumed to increase by fifty percent and the two-to-one rule is equivalent to a 0.08 fluctuation risk. If the 0.01 fluctuation risk used in Finland is accepted, the table shows that the two-to-one rule in effect assumes that expected claims in a bad year would increase by about twenty percent, a value at the bottom of the range actually computed by the Finns. This suggests that for an established company with a maximum net retention equal to the legal maximum, the two-to-one rule would probably be consistent with reasonable values for both parameters.

The one-to-one rule was adopted for fire insurance because of the possibility of greater fluctuations of claims in that line. The Finnish method provides a way of appraising this choice.

TABLE II 80

Risk Equivalents of the One-to-One Rule (Established Companies)

\begin{tabular}{ll|l|l|l|l}
\hline Bad year factors $\ldots \ldots \ldots \ldots$ & 0 & 0.20 & 0.40 & 0.70 \\
Fluctuation risk $\ldots \ldots \ldots$. & 0.00007 & 0.0005 & 0.002 & 0.01 \\
\hline
\end{tabular}

The shift in policy on claim fluctuations represented by the oneto-one rule may be analyzed by comparing the bad year allowances in

Using (1),

$$
\mathrm{U}+.976 \mathrm{p}=.976 \mathrm{My}_{a}\left[\frac{(1+\mathrm{q}) \mathrm{p}}{\mathrm{M}}\right] \text {. }
$$

In New York, the 2-to-1 rule dictates that net written premiums shall not exceed twice policyholders' surplus (U). Assuming that during the year net premium income (p) is one-half of net written premiums, as previously stated, and that written premiums are equal to earned premiums, we have $\mathrm{U}=\mathrm{p}$. Assuming that the maximum permitted single net retained risk is insured, $M=0.1 U=0.1 \mathrm{p}$. Therefore,

$$
1.976 \mathrm{p}=.976(.1 \mathrm{p}) \mathrm{y}_{a}\left[\frac{(1+\mathrm{q}) \mathrm{p}}{.1 \mathrm{p}}\right]
$$

or, $20.24=y_{a}[10(1+q)]$.

Assume $\mathrm{q}=.20$ and the result is

$$
20.24=\mathrm{y}_{a}[12] \text {. }
$$

Using tables of the Poisson distribution for an expected value of 12 , we find that the probability of 21 or more claims (the point of ruin) is 0.012 as shown in the table (rounded to 0.01 ).

79 Fluctuation risk is defined in note 77 supra.

so Same source and assumption as in Table I. See note 78 supra. The figures in Table II may be derived from the sample calculation given for Table I by setting $\mathrm{U}=2 \mathrm{p}$ in equation (3) of note 78 sipra. 
Tables I and II for the same fluctuation risk. Thus a 0.01 risk under the two-to-one rule has about a twenty percent bad year allowance associated with it, while the same risk under the one-to-one rule corresponds to about a seventy percent allowance. The one-to-one rule for fire insurance thus embodies the assumption that fluctuations in fire claims arising from changes in basic conditions are about three and one-half times greater than plausible average bad year allowances for other lines. ${ }^{81}$

Although data is lacking for the United States, the Finnish studies indicate that fire claim fluctuation is much closer to fluctuation in other lines than is indicated by this relation between the New York rules; probably it is not twice the average for other lines. ${ }^{82}$ Even assuming it to be twice this average, a 0.01 fluctuation risk would lead to approximately a three-to-two rule for fire insurance, or a one-third reduction in the amounts currently required.

Although the two-to-one rule may be defensible for established companies insuring the legal maximum single risk, it represents a much more stringent policy for companies electing not to compete for the largest contracts. This is because the rules are not correlated with the size distribution of potential claims, but only with their total amount as reflected in written premiums. In the safe bound method, the largest single risk is used as a surrogate for the probability distribution of claim sizes, and so the risk policy represented by the two-to-one rule changes with the size of that largest risk.

\section{TABLE III ${ }^{83}$}

Risk Equivalents of the Two-to-One Rule (Established Companies)

\begin{tabular}{c|l|l|l|l|l|l}
\hline $\begin{array}{l}\text { Bad year } \\
\text { factors }\end{array}$ & 0 & 0.10 & 0.20 & 0.30 & 0.40 & 0.50 \\
\hline $\begin{array}{c}\text { Fluctuation } \\
\text { risks when }\end{array}$ & & & & & & \\
MNR* equals : & & & & & & \\
$1 \%$ 84 & 085 & 0 & 0 & 0 & 0.000003 & 0.00002 \\
$5 \%$ & .00003 & .0002 & .001 & .004 & .01 & .03 \\
$10 \%$ & .002 & .005 & .01 & .03 & .05 & .08 \\
\hline
\end{tabular}

* Maximum single net retained risk as percent of surplus to policyholders.

81 The multiple would be larger for smaller values of $q$, and smaller for larger values, although in the latter case, the assumed $q$ value for the fire line would have to become so large as to be unreasonable.

82 The bad year factor for fire insurance is 0.40 in the Finnish system, while the smallest factor is 0.20 . GENERAL LETTER, supra note 49, at 12 .

83 Same source and assumption as in Table I. See note 78 supra. The $10 \%$ line of Table III is taken directly from Table $I$. The $5 \%$ line may be derived by setting $M=0.05 p$ in equation (3) of note 78 supra. The $1 \%$ line may be derived by setting $M=0.01 p$ in equation (3) of note 78 supra. 
The preceding table shows, for example, that allowing twenty percent for a bad year, a company with a legal maximum single risk (ten percent of policyholders' surplus) has a fluctuation risk of about 0.01 ; if the largest single risk is half of the maximum, the fluctuation risk is about 0.001 ; if a tenth of the maximum, the fluctuation risk is less than one in a million. Similar disparities appear in the full range of bad year factors.

The lack of consistency means that the two-to-one rule, or any rule based solely on a multiple of premiums, cannot be sustained in general as a reasonable accommodation between the risk of insolvency and the burden of reserves. If the rule is correct for companies at the legal limit for their largest single risk, it must be excessive as to others, and for some, vastly so. ${ }^{86}$ If it is correct for those companies with smaller maximum single risks, it is inadequate for those insuring the legal maximum.

Probably the most important consequence of the New York rules is the burden they impose on entering and growing companies. New York's statutory fixed minimum capital requirements have their principal effect on entering companies because the administrative rules will require reserves greater than the statutory reserves as a company's premium writings grow much past $\$ 4$ million. ${ }^{37}$ Beneath this premium level, statutory discrimination against smaller companies exists because statutorily required reserves will usually lie between $\$ 1$ million and $\$ 2$ million and this will exceed the amounts required even under the oneto-one rule for companies with less than $\$ 1$ million in written premiums. This distinct treatment of smaller companies-requiring reserves which bear a larger proportion to written premiums-may be advanced on the ground that smaller companies are likely to be subject to greater claim fluctuations than larger companies. To test the extent to which larger proportions of reserves could be justified on this basis, consider the situation if $\$ 1$ million is required as permanent capital. Expendable capital for start-up costs and permanent capital for liquidation expenses

84 These entries were calculated using the normal approximation to the Poisson distribution. For large expected values, the Poisson distribution approaches the normal distribution. The figures are from NAT'L BUREAU OF STANDARDS, TABLES of Noraral Probability Functions (1953).

85 Zero entries indicate a probability of less than 0.000001 .

${ }^{86}$ The theoretical conclusion that the 2 -to- 1 rule requires excessive resources is supported by a recent statistical study showing that for most lines of insurance, the industry-wide average of claims is less than $50 \%$ of the average net premium writings. Hofflander, Minimum Capital and Surplus Requirements for Multiple Line Insurance Companies: A New Approach, in INSURANCE, Governament and Soclal Policy: Studies In Insurance Regulation 69, 82-86 (S. Kimball \& H. Denenberg eds. 1969) (table 2).

87 See text accompanying notes 13-15 supra. 
are deemed covered by separate amounts. Using the safe bound approximation, and assuming that the maximum single net retained risk is ten percent of surplus, the fluctuation risks are given in Table IV.

TABLE IV ${ }^{88}$

Fluctuation Risks Assuming $\$ 1$ Million in ReQuired Surplus

\begin{tabular}{|c|c|c|c|c|c|c|}
\hline Bad year factor: & 0 & 0.10 & 0.20 & 0.30 & 0.40 & 0.50 \\
\hline $\begin{array}{l}\text { Fluctuation risk when } \\
\text { net written premiums } \\
\text { equal }(\$ 1,000): \\
10089 \\
250 \\
500 \\
750 \\
1,000\end{array}$ & $\begin{array}{l}0 \\
0 \\
.000002 \\
.00005 \\
.00007\end{array}$ & $\begin{array}{l}0 \\
0 \\
.000008 \\
.0001 \\
.0002\end{array}$ & $\begin{array}{l}0 \\
0 \\
.00002 \\
.0003 \\
.0005\end{array}$ & $\begin{array}{l}0 \\
0 \\
.00004 \\
.0006 \\
.001\end{array}$ & $\begin{array}{l}0 \\
0 \\
.00008 \\
.001 \\
.002\end{array}$ & $\begin{array}{l}0 \\
0 \\
.0002 \\
.002 \\
.005\end{array}$ \\
\hline
\end{tabular}

The table shows that for companies with written premiums up to $\$ 1$ million the risk of the total claims amount exceeding the statutorily required reserves is far smaller than under the two-to-one rule if that were applied solely to a larger company. The statutory rules thus represent for entering and small companies a significantly more stringent risk policy, which cannot be justified by reference to the possibility of greater fluctuations in claims.

As a company grows, it needs a greater absolute reserve due to increased expected losses. These losses for the coming year are generally estimated by multiplying the earned premiums for the preceding year (the portion of the written premium allocated to that year) by an average loss ratio (losses to earned premiums averaged over a number of recent years). Clearly the written premium, if different from the earned premium, would not be correct in this computation. Since the New York rules use written premiums, and since for a growing company written premiums exceed earned premiums, these rules overstate the increase in reserves required to cover growth. We measure the overstatement by comparing the reserves a growing company is required to add under the safe bound rules as a percentage of the required additions under the two-to-one rule. To make the comparison we assume a maximum net retention of ten percent of surplus and that the increase in earned premiums is one-third the increase in written pre-

88 Same source and assumption as in Table I. See note 78 supra. For the first entry of Table IV, set $p=0.1 U$ in equation (3) of note 78 supra. Then $p=0.05 U$ and $M=2 p$ in the same equation. These figures are then used in equation (3) of note 78 supra. Similar calculations yield the rest of Table IV.

89 Zero entries indicate a probability of less than 0.000001 . 
miums. Setting 0.01 as a reasonable fluctuation risk, Table $V$ shows the percentage relationships.

\section{TABLE V}

Increase in Safe Bound Reserves as a Percentage of INCREASE IN Two-to-ONE Reserves

\begin{tabular}{c|c|c|c|c|c|c}
\hline Bad year factors $\ldots . . . .$. & 0 & 0.10 & 0.20 & 0.30 & 0.40 & 0.50 \\
Percentage relationship ... & $22 \%$ & $31 \%$ & $40 \%$ & $49 \%$ & $57 \%$ & $65 \%$ \\
\hline
\end{tabular}

The table indicates that additions to reserves at the rate of between one-fifth and two-thirds the rate required by the two-to-one rule would preserve a consistent margin of safety in a growth situation; looking at the matter another way, under one set of assumptions, if the fluctuation risk under the two-to-one rule for an established company is 0.01 , the risk for a company whose written premiums have increased by thirty percent over the preceding year would be 0.008 ; if the increase were 150 percent, the risk would be $0.001 .^{90}$ Written premium rules thus impose an excessive burden on growing companies, the extent of that burden depending on the rate of growth.

The burden of the requirements on growing companies is compounded by the method of accounting for unearned premiums. Assume that the expenses of writing an additional $\$ 100$ in premiums are $\$ 40$, that expected loss claims over three years are $\$ 50$, and that a third of the written premium is earned in the current year and the balance deferred by crediting the unearned premium reserve. Under current accounting practice, the company deducts the entire $\$ 40$ as a current expense, deducts $\$ 17$ in loss claims, and carries the unearned premium reserve as a liability. The difference between the net increase in assets $(\$ 43)$ and the increase in liabilities (\$67) reduces policyholders' surplus by $\$ 24$. This depletion would be reversed in subsequent years when the balance of the premium is earned without additional charge. But since growing companies have a disproportionate number of first year policies, they continually drain policyholders' surplus in building up a prepaid expense equity in unearned premiums, a process which continues until the rate of growth declines. Meanwhile, the requirements of the administrative rules must be satisfied. Thus, in the above example, an additional policyholders' surplus of $\$ 74$ would be required to fund the increase of $\$ 100$ in premium writings.

Since most rapidly growing companies do not have sufficient surplus to meet the requirements of the New York rules, they use

90 To separate out effects it has been assumed in the above figures that the maximum single net retention grows with the company, always remaining at the legal maximum. If this were not true, disparities between the growth and established companies would be substantially greater than as stated. 
reinsurance to finance premium growth. The company pays to the reinsurer the proportion of the gross premium equal to the reinsurer's proportion of the risk assumed; the reinsurer pays to the company a commission in an amount such that the net premium retained by the reinsurer is sufficient to cover its portion of the expected loss claim plus expenses and profit. The company's net written premium is thus reduced, while its surplus benefits from substituting a current commission, which increases surplus, for later-accruing premiums, which are carried as a liability. By reinsurance, the company in effect borrows policyholders' surplus against its prepaid expense equity in unearned premiums. $^{\text {11 }}$

If the company in the above example reinsures half the $\$ 100$ policy, it would give up half the earned and unearned premiums in return for, say, a $\$ 21$ commission from the reinsurer and the reinsurer's assumption of half the claim loss. During the first year, the company's financial statement would show $\$ 50$ in net written premiums and $\$ 21$ in commission income against $\$ 40$ in expenses, $\$ 8$ in loss claims, and a $\$ 33$ increase in unearned premium liability, for a net decrease in surplus of $\$ 10$. Reserves required to finance this $\$ 100$ growth would thus be $\$ 35$ ( $\$ 25$ to cover the $\$ 50$ increase in net written premiums and $\$ 10$ to cover depletion of surplus). Under risk theoretic rules, assuming the risk standards of the two-to-one rule as set forth in Table I, the required reserves would be only slightly larger-some $\$ 41$ - and the company would not have the net $\$ 4$ cost of reinsurance ( $\$ 29$ reinsurance premium less $\$ 25$ loss claim assumed by the reinsurer). The example illustrates that by reducing the reserves required for growth, even safe bound risk theoretic methods should permit substantial savings in reinsurance premiums.

\section{Conchusion}

Risk theoretic analysis reveals significant defects in New York's solvency control rules. The New York statutes impose unnecessary burdens on entering and very small companies because they require fixed dollar amounts of capital without reference to premium income or other measures of expected losses. The Department of Insurance's administrative rules based on written premiums discriminate against companies not competing for the largest policies and against those in rapid growth: the first because the rules ignore the size distributions of retained risks, and the second because they make no allowance for the lag between earned and written premiums. Entering companies are

91 For a discussion, see 1 Munich Reinsurance Co., Reinsurance and REASSURANCE 3-8 (1963). 
also at a disadvantage compared to established companies because of the Department's previously mentioned policy of relaxing the administrative rules in favor of companies with a history of profitable operations. ${ }^{92}$ While this may be justifiable in terms of solvency protection, the discrimination against new entrants emphasizes that the stated rules should be no stricter than solvency considerations would dictate when underwriting skill has yet to be established. The special burden of the present rules on entering and growing companies may have an unnecessary chilling effect on competition and on expansion of industry capacity.

This much is deducible from, or at least suggested by, theoretical considerations without reference to empirical data. If some reasonable assumptions are made concerning claim statistics, it appears that the two-to-one rule may not be overly stringent in all situations, but that the one-to-one rule probably represents an extreme view of the extent of fluctuation in fire and marine claims. A definitive judgment as to the acceptability of these rules, however, would have to await study of claim materials and decision on risk policies.

If the Finnish experience is a fair guide, the introduction of risk theoretic rules should most significantly affect reinsurance practices. By reducing reserve requirements, total reinsurance should be reduced. In Finland, reinsurance premiums as a percentage of total premiums for fire insurance declined from about fifty percent when the equalization reserve was introduced in 1953 to about thirty-three percent in 1957; the figures for transport insurance were about seventy percent and fifty-eight percent, respectively. ${ }^{93}$ Further declines may occur as the full impact of the changes made in 1965 is realized. Under rating systems commonly used in the United States, the cost of reinsurance is passed on to the consumer in the form of higher premium rates. ${ }^{04}$ Consequently, if comparable reductions in reinsurance were effected here, there should be substantial savings for consumers, particularly in the case of rapidly growing companies.

In defining more precisely and persuasively the reserves actually required for solvency, risk theoretic methods should throw into sharp

82 Text accompanying note 20 supra.

93 See Pentikäinen, Fluctuation Reserve: $A$ Technique to Take lnto Account the Fluctuation of the Risk Business When Calculating the Technical Reserves of Insurance Companies, 1970 Ins. IN Finland, No. 1, at 3, 7.

04 Reinsurance premiums paid by a company will normally exceed the losses paid by the reinsurer. As a result, a reinsurance program will increase the loss ratio (the ratio of net losses paid by the company to net premiums retained by the company after deduction of payments to reinsurers). Since overall premium rates are commonly set so that, after deduction of expenses and an allowance for profit, the remaining proportion of premium dollar equals the loss ratio (averaged over several recent years), an increase in the loss ratio leads directly to an increase in rates. 
relief the propriety of present practices by which policyholders bear the total cost of reinsurance. This issue has not arisen in Finland probably because Finnish companies lack the extensive resources of American companies. But since free reserves of companies here are extensive and are frequently used in acquisition programs through conglomerates-to the benefit of stockholders-it seems reasonable for policyholders to carry only that portion of reinsurance costs needed to protect solvency, while reinsurance costs above that level should not be considered in setting premium rates. ${ }^{95}$

When mathematical methods are used in the law, the fear is sometimes expressed that with some mathematical twist or seemingly innocent shift in input, the cognoscenti can manipulate the techniques for their benefit. In constructing their regulations, the Finns were concerned with the problem of technicality, but from a different point of view. The regulators promoted risk theoretic methods but, to facilitate compliance, sought techniques that could easily be applied, even by those who did not understand them. In fact, the essence of the Finnish method is not the application of computer techniques to the problem of solvency control, but the distillation of very simple rules from a highly complicated and technical branch of probability theory.

The safe bound methods applicable to the great majority of companies are so simple, and their basis so clearly revealed, that manipulation is difficult to envision short of simple fraud in reporting, a risk under any system. When "exact" methods are required, companies will usually use the normal power approximation; this would require a computer except that prepared tables reduce the computation to a trivial matter of substitution in a formula. In the exceptional cases governed by neither the safe bound rules nor the normal power approximation, the computation is more complex. The failure, however, to satisfy requirements of more simple methods means that the company is much closer to danger and its status deserves more careful consideration. By sharpening the focus of regulatory concern, risk theoretic methods should reduce the opportunities for manipulation, even in the exceptional case where the level of technicality is substantial.

It may be objected that the Finnish method does not yield an accurate measure of the fluctuation risk and does not in fact even purport to do so. This is true. The use of safe bound assumptions at several points means that the computed risk is overstated, but the degree of overstatement cannot be estimated without complicated effort. More-

${ }^{95}$ Cf. Hearings on Leasco Data Processing Corp. Before the House Antitrust Subcomm. of the House Comm. on the Judiciary, 91st Cong., 2d Sess., ser. 23, pt. 2, at 32 (1970) (remarks of Representative Celler). 
over, as we have observed, making allowances for bad years precludes a precise specification of risk, even assuming no overstatement in the methods of approximation. Greater precision is attainable in theory but would require more data and more complex calculations.

The Finns in fact made a decision common in the law: they traded precision of result for certainty and simplicity in application. It should be noted, however, that the formal regulations merely require that mathematical methods be used to compute reserves sufficient to keep the fluctuation risk under 0.01 . The technique by which this is done is left open, and a company may use methods different from those suggested if it can demonstrate that accuracy would be improved by the substitution. Thus the basic regulatory decision was to require a mathematical approach to the problem of solvency and a specification of the degree of acceptable risk. Within this framework, the methods of computation can become as accurate as the companies undertake to make them. Meanwhile, the public interest is protected by "safe" methods.

The fluctuation risk is not of course the only threat to solvency. There are many others, but probably the most frequently discussed is the danger of investment losses from declines in the securities markets. This problem is less visible in Finland where insurance companies invest principally in debt and do not have the common stock portfolios which are held by American companies and subject to much greater fluctuations in value.

But this problem was recognized in Finland, and by omitting it from mathematical consideration the Finns in effect treated market fluctuation as a problem distinct from claims fluctuation. This seems correct: the extent of market risk depends on the nature of the investment portfolio and other factors relatively unrelated to claims risk. ${ }^{96}$ To squeeze both market and claims risks under a single written premium rule implies that regulation cannot in any realistic sense rest on an informed judgment as to the degree of danger from each source. It is generally accepted that protection from investment losses calls for a conservative valuation of portfolio securities, and there would be no conflict between the use of a conservative rule in this valuation and the simultaneous use of risk theoretic methods to estimate the fluctuation risk. $^{97}$

96 A study has shown that claims losses and return on investment are in fact independent phenomena. See Lambert \& Hofflander, The Impact of New Multiple Line Underveriting on Investinent Portfolios of Property-Liability Insurers, $33 \mathrm{~J}$. RIsk \& INS. 209-33 (1966).

97 An appropriate rule could be built on statistics of variations in securities prices. See Hofflander, Minimum Capital and Surplus Requirements for Multiple Line Insurance Companies: $A$ New Approach, in Insurance, Governarent and Social Policy: 
To what extent does the Finnish method depend on particular conditions, not likely to be duplicated in a different regulatory setting? The exact method depends on the probability distribution of claim sizes, and this must reflect claim statistics. It is, however, a mathematical fact that differences in the shapes of these distributions within the range encountered in practice will not change the results by much. And, as previously noted, the safe bound methods applicable to most companies use the maximum claim as a safe approximation for the distribution function of claim sizes, and thus are not to any extent dependent on the shape of those distributions or on the parochial claim experiences underlying them. Of course, the bad year factors must be set, and the policy decisions there involved should be predicated upon the experience of variations in claims. But because the factors being measured are to reflect abnormalities, a frequent updating of the experience would not seem necessary; and requiring the regulatory authority to take systematic cognizance of its experience from time to time is not unduly onerous. Indeed, the present two-to-one and one-to-one rules represent just such an intuitive appreciation of experience in the 1930's.

If it had been necessary to compute exact probabilities of ruin in Finland, the objective of simplicity could not have been achieved. But this was not necessary; to avoid complexities which might introduce errors, the model builders chose safe approximations as simplifying assumptions at various points in the method. No one knows how much was denied to accuracy in these choices. It is nevertheless striking that despite compromises with perfection the results read so strongly on rules formed by educated intuition.

Studies IN Insurance Regulation 69 (S. Kimball \& H. Denenberg eds. 1969). A theoretical development appears in ARTHUR D. LitTle, INC., PRICEs aNd PRofits IN THE PROPERTY' AND LiABIITY INSURANCE INDUSTRY E-8 (1967) (a report to the American Insurance Association). 